\title{
A method to generate energy value-streams in production and logistics in respect of time- and energy-consumption
}

\author{
Egon Müller • Timo Stock • Rainer Schillig
}

Received: 25 July 2013/ Accepted: 19 November 2013/Published online: 5 December 2013

(C) The Author(s) 2013. This article is published with open access at Springerlink.com

\begin{abstract}
In the industry, Lean Production Systems have been successfully used for years to reduce lead times. The value-stream mapping method (VSM) has proven itself to be the best practice tool for this purpose. With this method process steps can easily be divided into value-adding and non value-adding ones. However, the VSM does not provide any information about the production process energy consumption and, as a consequence, it does not give any hint at how much of the energy used actually serves valueadding purposes. Also transportation and logistics have not been analyzed by their time- and energy-efficiency up to now. Would it be known how much energy is used for value-adding and for necessary process steps, then it would be possible to optimize value-streams in a holistic way, simultaneously considering time- and energy-consumption. This paper describes how the VSM can be extended to an energy value-stream mapping method (EVSM) by maintaining its original character and its inner logic. Furthermore transportation processes and the related time and energy input have been added to the EVSM.
\end{abstract}

Keywords Energy value-stream mapping - Energy efficient production and logistics · Lean and Green Manufacturing

E. Müller · T. Stock $(\bowtie)$

Institute of Industrial Management and Factory Systems, University of Technology Chemnitz, Chemnitz, Germany

e-mail: timo.stock@htw-aalen.de

T. Stock $\cdot$ R. Schillig

Professorship of Production Engineering and Process

Management, University of Applied Sciences Aalen, Aalen, Germany

\section{Introduction}

While the manufacturing industry is one of the main energy consumers, it is at the same time also the key factor for our prosperity. Considering the continuously rising energy cost and an increasing public awareness of the need for a sustainable economic activity, many branches of industry have in the meantime declared energy efficiency their strategic business objective.

During the second half of the last century, labour productivity has increased almost fourfold, while energy productivity has not even doubled during the same period of time [1]. In the past, the industry's rationalizing efforts have focused on increasing the degrees of automation while simultaneously cutting down the cycle times.

When in the nineties of the last century the methods of the Toyota Production System (TPS) came to be known in the Western World, numerous companies tried to adopt them for their own use. Since that time the TPS is considered as a benchmark for creating highly efficient valuestreams and very often it is also described as a lean production system.

\section{The Toyota production system}

Taiichi Ohno, who is one of the TPS's architects, describes its essence as follows: 'All we are doing is looking at the time line from the moment the customer gives us an order to the moment when we collect the cash. And we are reducing that time line by removing the non value-added wastes' [2]. So, the point in the TPS is to keep the time interval between the placement of an order and the payment of the product as short as possible. Therefore, the creation of value should be as efficient as possible, in other 
words it should be achieved while avoiding waste. To accomplish this, non value-adding processes (waste) should be eliminated wherever possible. If complete elimination is not possible waste should be at least reduced to a minimum. To identify non value-adding processes systematically, Ohno classified the types of waste as follows [2]:

- Waste of overproduction

- Waste of time on hand (waiting)

- Waste in transportation

- Waste of processing itself

- Waste of stock on hand (inventory)

- Waste of movement

- Waste of making defective products

That means, waste is everything that is not immediately value-adding [2] or, as Masaaki Imai puts it: 'In gemba, only two types of activities go on: value-adding and non value-adding' [3]. He thereby makes it quite clear that a process step is either value-adding or non value-adding. This dualistic view has proven itself to be the best practice tool to achieve high efficient value-streams.

Usually, the creation of value requires an input of time and energy. Waste in the sense of the TPS is almost always regarded as waste of time. But when time is wasted and during this time energy is consumed, this amount of energy necessarily also has to be regarded as waste [4].

The types of waste listed above seen from an energyrelated perspective are:

\section{- Waste of overproduction}

Overproduction requires time and it usually generates additional energy costs. It also causes inventories and unnecessary transport and that, too, entails additional energy inputs.

- Waste of time on hand (waiting)

During the time machines stand ready for operation, most of them require energy. Their energy consumption in the stand-by mode or in the ready to operate state often reaches levels that are similar to those found in productive operation.

- Waste in transportation

Transport by its nature does not increase the value of the product. For the most part, however, it involves an necessary input of energy.

- Waste of processing itself

Designs, manufacturing technologies and process flows not suited for their intended purpose as well as tools of poor quality entail an energy input that is needlessly high.
- Waste of stock on hand (inventory)

Unnecessary stocks waste energy by the additional transport and the storage area they require, by air conditioning, warehouse management, etc.

- Waste of movement

Every kind of movement in machinery or equipment usually requires energy. If the movement does not add any value to the product, its energy consumption is waste.

- Waste of making defective products

Reworking itself as well as the processes required for reworking need energy. When rejects have been produced, the whole energy used thus far is waste and must be spent anew. In addition the disposal or recycling of such products also requires energy.

It may therefore be taken for granted that lean production systems are more efficient than traditional mass production systems because they do have shorter lead times [5]. A lesser input of time however has a direct impact on the energy consumption due to the simple fact, that energy is a function of time and electrical power.

\section{Value-stream mapping and energy value-stream mapping}

With their value-stream mapping that Rother and Shook [6] presented in 1999, for the first time a method appeared on the scene which was apt for practical use and made it possible to look at the cycle times separately from the non value-adding lead time. With this method they followed the inner logic of the TPS, namely to differentiate the processes of a value-stream into the two categories 'value-adding' and 'non value-adding', only. In their approach, minimizing the lead time was in the focus of their interest. They contrasted the production lead time with the sum of the cycle times-which they called processing time. This shows clearly the lead time extending effect of a batch-oriented production (see Fig. 1 above).

Though Rother and Shook did make a distinction between value-creating time and cycle time, in their VSM graphics the processing time is consistently represented as the sum of the cycle times (Fig. 1 above). This may convey the impression that the process sequences within the cycle times are, as a matter of principle, free from waste. However, this is not so. When taking a closer look, one can see almost always that the cycle time, in other words the manufacturing process itself, is composed of value-adding $\left(\mathrm{t}_{\mathrm{va}}=\right.$ time value-adding) and non value-adding ( $\mathrm{t}_{\mathrm{nva}}=$ time non value-adding) amounts of time [7]. The same applies to 


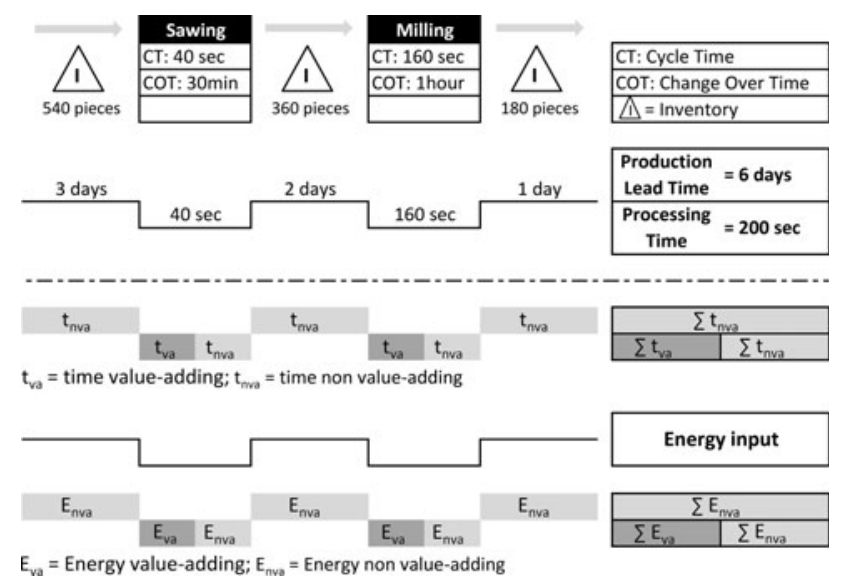

Fig. 1 VSM according to [6] and schematic representation of valueadding and non value-adding input of time and energy

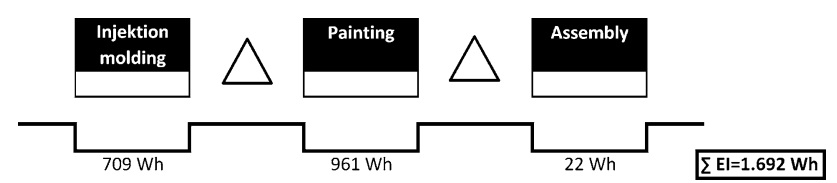

Fig. 2 Extension of a VSM to an EVSM according to [8]

the energy input of the manufacturing processes. This is represented schematically in Fig. 1 below. The processes outside the cycle time are classified as non value-adding.

There are several proposals in order to extend the VSM to an EVSM [8-14]. All these approaches have a stepped 'energy line' for the visualisation of the energy input alongside the process chain (Fig. 2). However none of these proposals is built on an exclusively dual assessment of the time and energy input only referring to the criteria value-adding or not.

To reveal waste in a particular process it is necessary to divide the process time into value-adding and non value-adding parts. The energy which is used during a non value-adding process part necessarily has to be regarded as waste (of energy). Only the energy which is used during a value-adding part can be regarded as value-adding energy.

This dualistic approach is not limited on production processes only. It can easily be extended to transportation processes as shown later in paragraph 8 .

In cooperation with the Chemnitz University of Technology, Aalen University of Applied Sciences has developed a method allowing for appraising the process-related input of energy using the criteria 'value-adding' and 'non value-adding'. This dual approach allows for the first time to extend the proven VSM method to an EVSM, in concordance with the principles of the TPS.

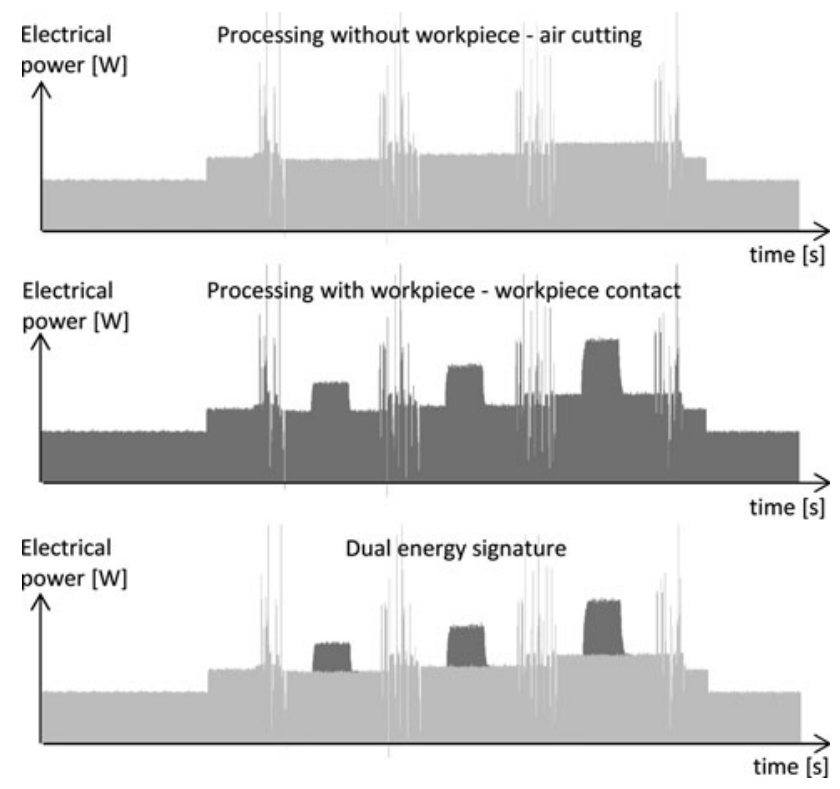

Fig. 3 Chip removal-air cutting versus workpiece contact

\section{Creating dual energy signatures, using the example of a chip removal process}

In the Aalen University's chip removal laboratory power measurements were taken on a 3-axis vertical machining centre, Hermle Type C $30 \mathrm{~V}$.

The machining process consisted in successively milling three grooves of different widths into a component made from heat-treated steel $\mathrm{C} 45$. Chip removal was done in full cut, with an infeed of $7.5 \mathrm{~mm}$ over a distance of $60 \mathrm{~mm}$ and using three HSS end mill cutters with diameters 8,12 , and $16 \mathrm{~mm}$. In parallel, a power measurement was taken using a portable wattmeter [15].

The test set-up had a distinctive feature in so far as the first pass took place using an 'air cut', in other words processing without a workpiece (Fig. 3, top). This made it possible to see what the energy signature of the process looked like without a workpiece contact. The second pass took place with workpiece contact (Fig. 3, centre). When both signatures are overlaid one gets the dual energy signature (Fig. 3, bottom). In this signature the value-adding elements of the process are clearly distinguishable, with regard to their duration as well as with regard to the input of energy, and can be differentiated unmistakably from the non value-adding elements of the process.

Details of these measurements are shown in Fig. 4. The light grey signature shows the electrical power consumption during air cut, while the dark grey signature shows the additional power consumption during chip removal. 


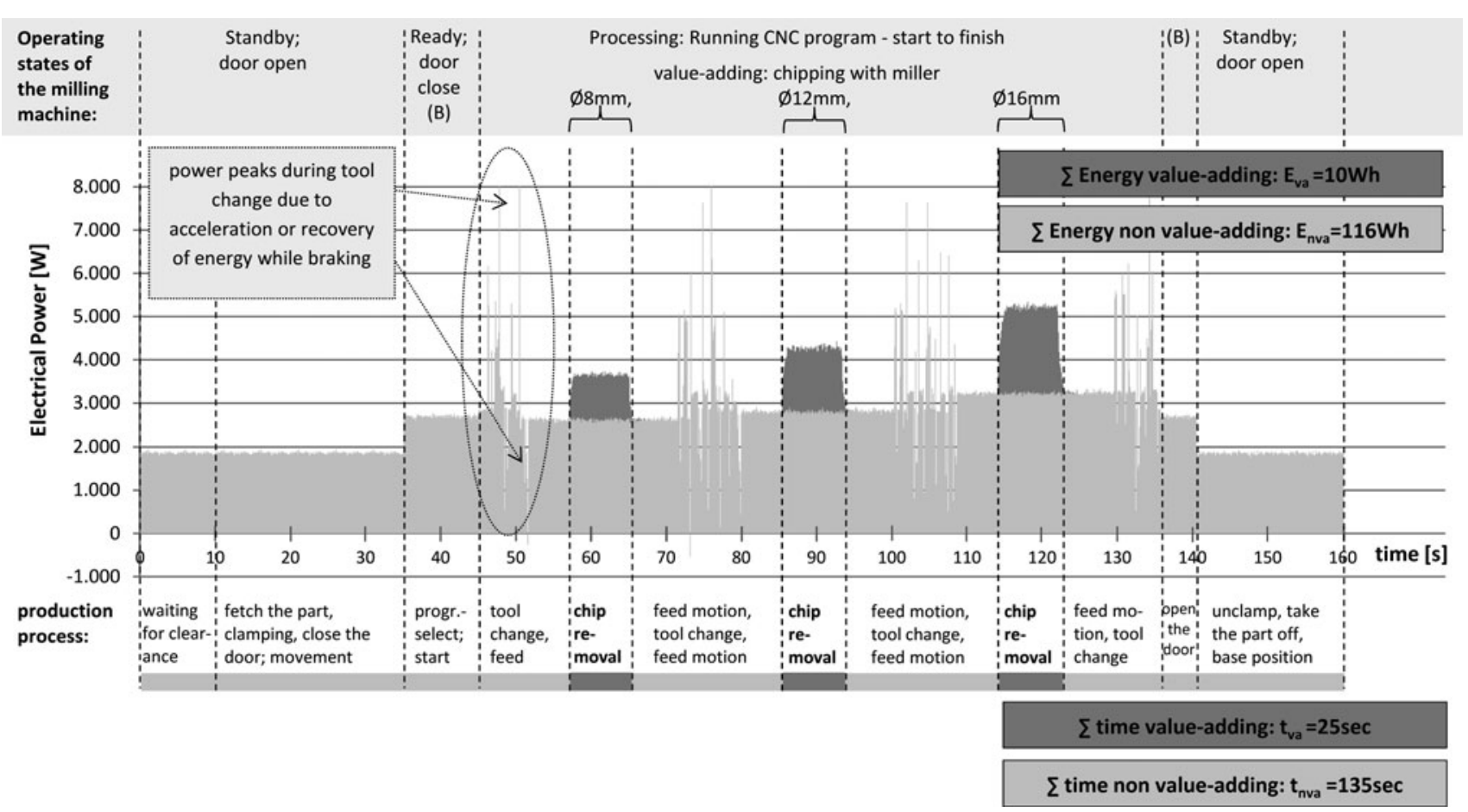

Fig. 4 Dual energy and time signature of a chip removal process

Fig. 5 Dual signature and extended data box
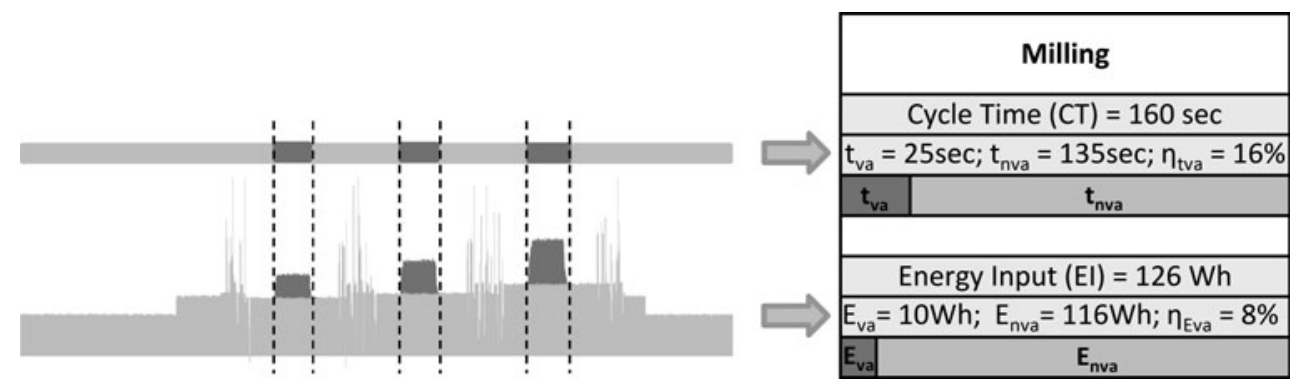

Only the actual chip removal process is value-adding. The value-adding times are marked by dark grey bars at the bottom

The value-adding energy directly required for chip removal is $10 \mathrm{Wh}$, the value-adding time needed is $25 \mathrm{~s}$ in total. The non value-adding input of energy is $116 \mathrm{Wh}$, while the non value-adding input of time is $135 \mathrm{~s}$ [16].

\section{Dual resolution of cycle time and energy input}

The value-adding efficiency of the process in terms of energy, $\eta_{\text {Eva }}$, as well as the value-adding efficiency in terms of time, $\eta_{\text {tva }}$, can now be defined.

$$
\begin{aligned}
& \eta_{\mathrm{Eva}}=\frac{E_{\mathrm{va}}}{\left(E_{\mathrm{va}}+E_{\mathrm{nva}}\right)} \quad \eta_{\mathrm{Eva}}=\frac{10 \mathrm{Wh}}{(10 \mathrm{Wh}+116 \mathrm{Wh})}=8 \% \\
& \eta_{\mathrm{tva}}=\frac{t_{\mathrm{va}}}{\left(t_{\mathrm{va}}+t_{\mathrm{nva}}\right)} \quad \eta_{\mathrm{tva}}=\frac{25 \mathrm{~s}}{(25 \mathrm{~s}+135 \mathrm{~s})}=16 \%
\end{aligned}
$$

Equation 1: Value-adding efficiencies and calculation example

The use of dual signatures allows to evaluate the production process in respect to the efficient usage of time and energy. The cycle time itself as well as the energy input within the cycle time are thereby consequently subdivided into value-adding and non value-adding parts. In the extended data box of the milling process (Fig. 5), the results are shown nominally, in form of figures, as well as proportionally in form of the bars beneath.

The hypothesis that the entire cycle time is completely value-adding, which up to now has been considered valid, must be abandoned as not being correct. In addition the low efficiencies to be seen in Fig. 5 also indicate that the dual approach can help reveal substantial improvement potentials.

Up to now the authors have analyzed several production processes like milling, casting, welding, injection moulding, handling, robotic and laser applications. For all of 


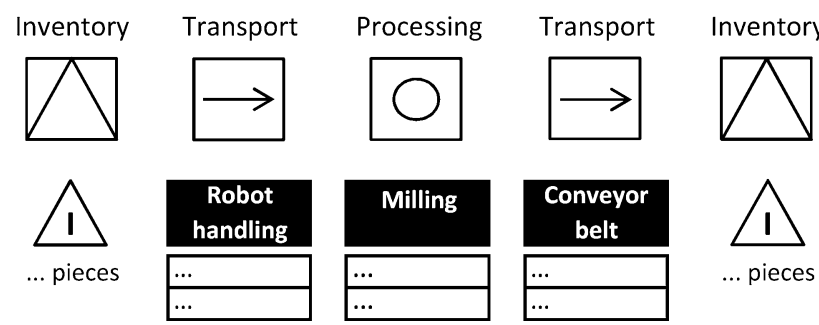

Fig. 6 Example of a functional chain according to [17]

them a dualistic approach can be made. Other processes are under research.

\section{Integration of transport into energy value-stream mapping}

Reducing inventories is one significant field of action of the VSM. However, a typical functional chain does not consist of inventories and processing only, but usually also involves transport (Fig. 6).

The time used for in-plant transport has so far hardly been taken into account in VSMs although it has a lead timeextending effect. For the EVSM it is therefore necessary to integrate the input of energy caused by transport, because the in-plant logistics has quite a significant share in the total energy consumption of the factory $[18,19]$. In addition, the transport-related energy input, apart from not being valueadding, also generates costs. From an economic point of view it is therefore reasonable to minimize this cost factor.

Figure 6 shows an example of a batch-oriented valuestream. Transportation is, by its nature, usually not a valueadding process. It only changes the location or the place of the product. However, it is hardly possible to have all value-adding processes take place at one single location; transportation is in many cases necessary. Therefore, as shown in Sect. 2, Ohno does not speak of 'waste of transportation' but of 'waste in transportation'. To make it clear, Transportation usually cannot add any value to a product, but nevertheless in some cases is necessary. The question arises whether transportation can also be described by using a similar method like the dual approach. This is discussed using the example of a usual conveyor belt. Figure 7 shows the electrical power consumption in three different process segments:

- A: Conveyor belt has not yet been loaded

- B: Conveyor belt is loaded

- C: Conveyor belt has been unloaded

Looking at transportation in terms of time, only transportation in the loaded condition (B) is considered to be necessary $\left(\mathrm{t}_{\mathrm{Tn}}=\right.$ time Transport necessary). Process segments (A) and (C) do not change the place of the product by the conveyor and therefore this transports are not necessary ( $\mathrm{t}_{\mathrm{Tnn}}=$ time Transport non necessary).

When looking at transportation under energy-related aspects, the idea of the 'air cut' can in principle also be applied. The energy requirement of the transport system is slightly higher when it is moving in the laden condition (Fig. 7b) than when it is moving in the unladen condition (Fig. 7a, c). The energy input which accounts for the transportation of the product is shown by the energy consumption $\mathrm{E}_{\mathrm{Tn}}$ (= Energy Transport necessary).

In consequence also the time and energy required in transportation can be divided into necessary and non necessary. The data box (Fig. 7) shows the results of the survey.

\section{Energy value-stream mapping}

The analysis of the manufacturing and transport processes by means of dual signatures allows it to extend the VSM to an EVSM while maintaining the VSM's inner logic. To establish the EVSM, the first thing to do is to draw the data boxes of the value-stream including the transport processes (Fig. 8). In keeping with the rectangular function of the time line, a rectangular function of the energy line should be mapped in the graph. This way, by analogy with the type
Fig. 7 Dual signature and data box transport conveyor belt

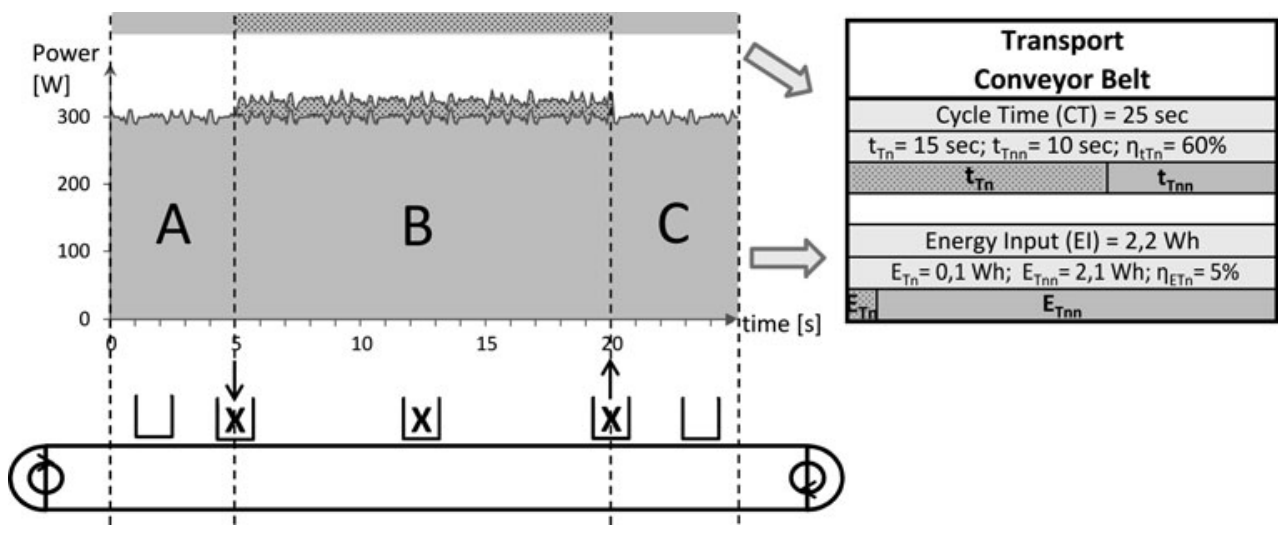




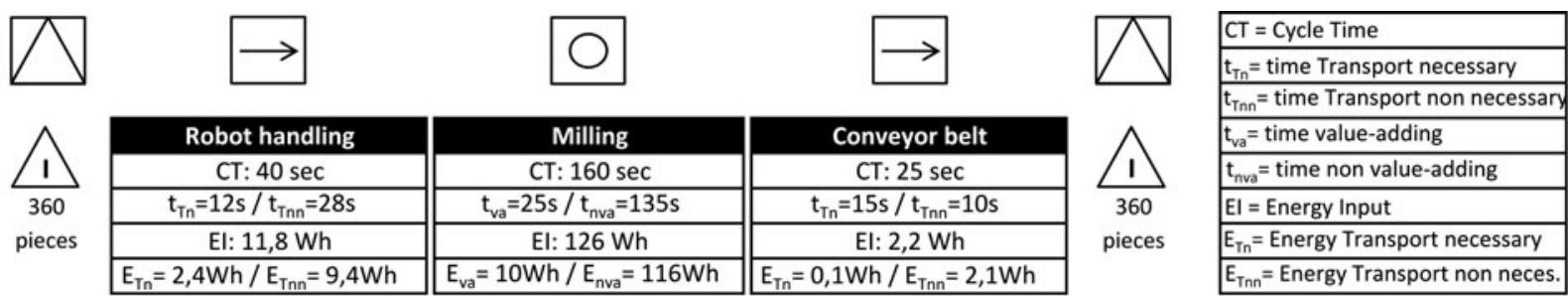

\begin{tabular}{|c|c|c|c|c|c|c|c|}
\hline \multirow{2}{*}{ Time } & 2 days & & & & 2 days & $\sum$ Waiting Time: & 4 days \\
\hline & \multirow{2}{*}{\multicolumn{2}{|c|}{$t_{T n}=12 \mathrm{~s} \quad t_{T n n}=28 \mathrm{sec}$}} & \multirow[b]{2}{*}{$160 \mathrm{sec}$} & \multicolumn{2}{|l|}{$25 \mathrm{sec}$} & ETransport Time: & $65 \mathrm{sec}$ \\
\hline & & & & $t_{T n}=15 s$ & $t_{T n n}=10 \mathrm{~s}$ & $\sum$ Processing Time: & $160 \mathrm{sec}$ \\
\hline & & & & & & $\sum \mathrm{t}_{\mathrm{va}}^{\prime}=25 \mathrm{~s} ; \sum \mathrm{t}_{\mathrm{nva}}^{\prime}=20$ & $l_{\text {tva }}=11 \%$ \\
\hline
\end{tabular}

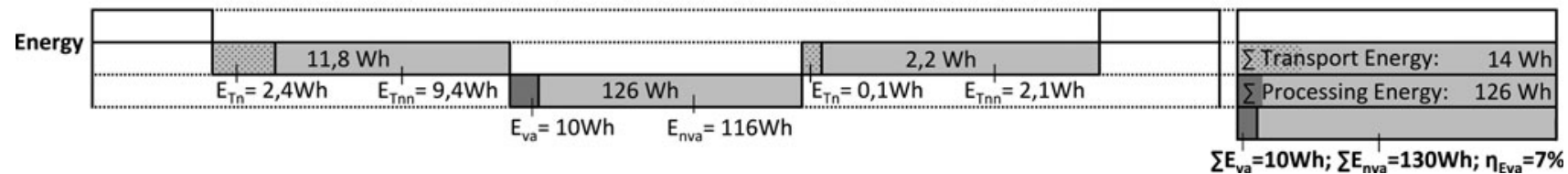

Fig. 8 Energy value-stream mapping

of waste inventories, also the transports and the energy inputs associated to them can be visualized.

- Top line: Waiting times/idle periods (Inventory)

- Intermediate line: Transportation times (Cycle times)

- Bottom line: Processing times (Cycle times)

$\mathrm{t}_{\mathrm{Tn}} / \mathrm{t}_{\mathrm{Tnn}}$ within the transport time and $\mathrm{t}_{\mathrm{va}} / \mathrm{t}_{\mathrm{nva}}$ within the processing time are shown proportionally in form of bars, as well as nominally in form of figures (Fig. 8, time line). The sums of the different times and the portion of $\mathrm{t}_{\mathrm{Tn}} / \mathrm{t}_{\mathrm{Tnn}}$ and $\mathrm{t}_{\mathrm{va}} / \mathrm{t}_{\mathrm{nva}}$ are shown at the right-hand side of the time line.

From the view point of the customer, only $t_{v a}$ during processing serves value-adding purposes, therefore the overall value-adding efficiency in terms of time can be calculated as follows:

$\eta_{\mathrm{tva}}=\frac{\sum t_{\mathrm{va}}}{\sum\left(t_{\mathrm{va}}+t_{\mathrm{nva}}\right)+\sum\left(t_{\mathrm{Tn}}+t_{\mathrm{Tnn}}\right)}$

Equation 2: Overall value-adding efficiency in terms of time. The result of Eq. 2 is also shown proportionally in form of bars in Fig. 8 on the right hand side beneath the data box. If the non value-adding waiting times would be included in this evaluation, then the portion of $t_{\mathrm{va}}$ would almost be invisible. The same logic can be applied to the use of energy in EVSM (Fig. 8, bottom line).

\section{Peripherals model and energy value-stream mapping}

In addition to the main processes and the transport processes, a number of peripheral auxiliary processes contribute to the overall energy requirement of a factory. Schenk \& Wirth's Model of Peripheral Order [20] is

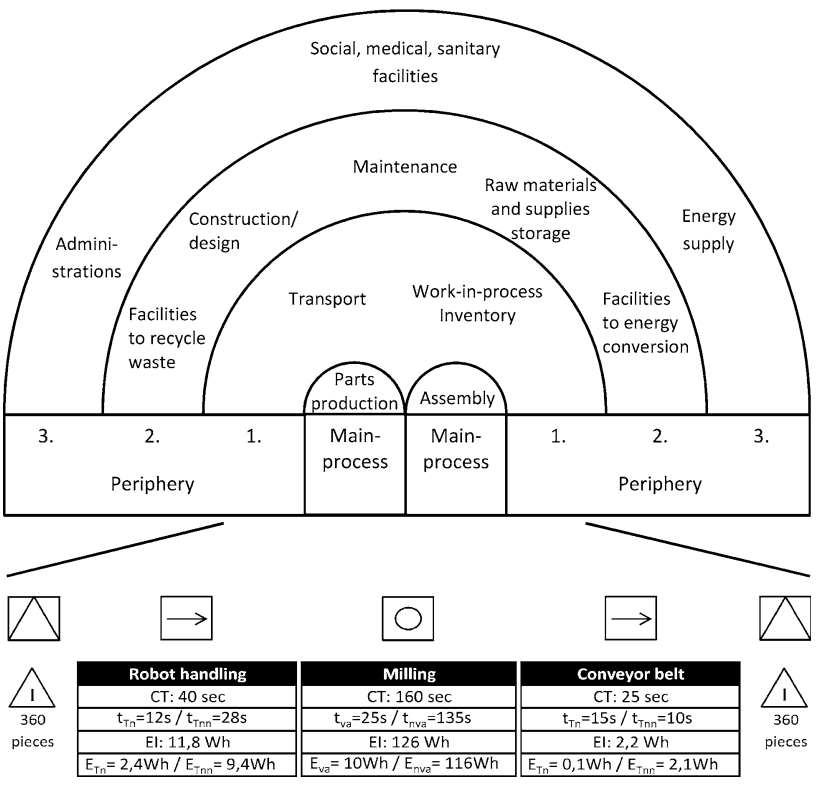

Fig. 9 Peripheral model and energy value-stream mapping

particularly suited to visualize the energy consumption, with the main processes in the centre and the numerous auxiliary processes at the peripheries.

By means of this model the energy requirement in an organization is subdivided into that of the main processes and that of three peripheries [21]. While a manufacturing or assembly progress is brought about on the workpiece by the main processes, the peripheral auxiliary processes ensure that the main processes can work properly [17].

Like discussed above, only $\mathrm{t}_{\mathrm{va}}$ and $\mathrm{E}_{\mathrm{va}}$ during processing ( = main-process-Fig. 9) serves value adding purposes. The time and energy used for transportation and inventories ( $\hat{=}$ 1. Peripherie-Fig. 9) doesn't serve any value- 
adding purposes. Thus the EVSM with its associated inplant transport processes presented in this essay can be linked easily with the peripherals model (Fig. 9).

Please be aware that this is only a basic overview of the application of the dualistic approach to energy signatures.

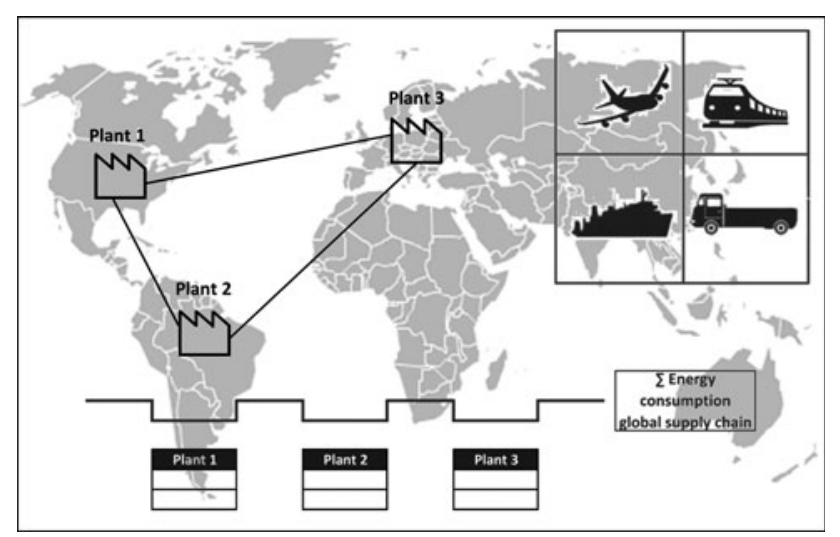

Fig. 10 Drawing an energy balance of the global value-streams by means of energy value-stream mapping
How to improve a specified process steps in detail needs more information and will be published soon.

\section{Using energy value-stream mapping to look at global supply chains}

When the VSM is extended to an EVSM, not only the inplant production and logistics processes should be taken into account but also external processes. Globalization entails the formation of worldwide and highly complex supply chains and, as a result, leads to an enormous increase in the worldwide flows of commodities. It has to be expected, that in the medium term, the overall energy footprint of a product will become a competitive factor that should be taken very seriously. At that time at the latest it will be necessary to draw an energy balance of the entire value-stream, beginning at the raw material and ending at the disposal of a product. The life cycle carbon footprint of a product would then become an integral part of its specification, which means that airfreight, rail transport,

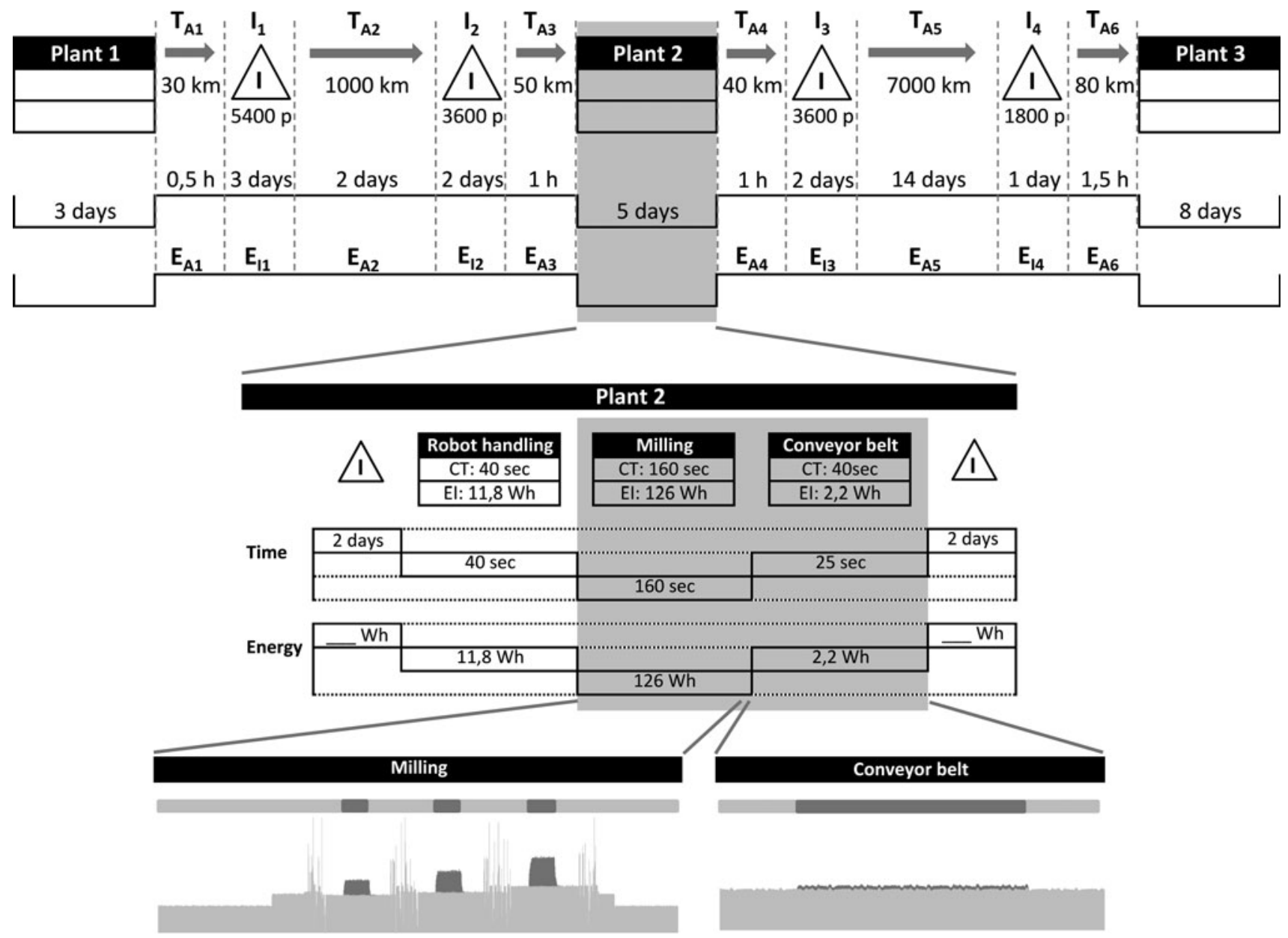

Fig. 11 EVSM overall view-from the global flow of commodities to a detailed view on processes 
navigation, and truck transport will have to be integrated into the energy value-stream mapping, too. As shown in Fig. 10, EVSM is also ideally suited to look at global interplant transports.

Figure 11 shows this matter in some more detail. The exemplary logistics chain shown at the top is composed as follows: Transport $\mathrm{T}_{\mathrm{A} 1}$ from Plant 1 to the warehouse $\mathrm{I}_{1}$ of an area freight forwarder, then Transport $T_{A 2}$ across a bigger distance to the next warehouse $\mathrm{I}_{2}$, then $\mathrm{T}_{\mathrm{A} 3}$ to Plant 2.

The rectangular function for transport and storage between plants is offset upwards, meaning that these two types of processes are non value-adding. The lead times in the plants are offset downwards as they are, at least partially, value-adding. In the energy line beneath, the energy requirements $\mathrm{E}_{\mathrm{A} 1}, \ldots, \mathrm{E}_{\mathrm{A} 6}$ of external transport and storage

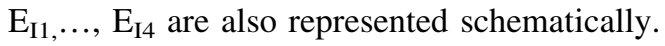

Both types of processes require energy, and according to the TPS both are classical types of waste. Therefore, as far as storage and transport of the products are concerned, the energy line is offset upwards, very much like the time line. The central part of Fig. 11 represents a schematic view of the processes that take place in Plant 2. This part was explained in detail above (Fig. 8).

Here, too, the transport and storage processes are considered non value-adding. Only the time and the energy of the manufacturing processes themselves are, at least partially, value-adding. This is shown schematically by the signatures in the bottom part of Fig. 11.

Using the suggested EVSM method, complex valuestreams can be investigated in their entirety. One and the same logic can be used to analyse in-plant as well as external process chains time-wise and energy-wise. If all sub-processes are investigated with regard to the valueadding and the non value-adding inputs of time and energy (Fig. 11, bottom), then it is possible to make up a dual balance for complex value-streams by contrasting the sum of the value-adding time and energy demand with the sum of the non value-adding demand.

\section{Summary}

Designing time- and energy-efficient value-streams is becoming more and more important in the manufacturing industry. With the help of dual energy signatures the valueadding and the non value-adding inputs of time and energy can be determined.

This is shown using the example of a chip removal process, in which the energy requirement during air cutting is contrasted with the energy requirement for a cutting operation with workpiece contact.
This distinction makes it possible to extend a VSM, for a start, by adding a detailed dual temporal view on the processing and transport processes. Then, with this analysis a dual energetic view is possible, too. Only a consistent reduction to a dual approach will make it possible to subject the technology used to critical analysis in respect of its time and energy balances.

Including transport in the EVSM offers the opportunity of visualizing not only its lead time-extending effect but also its non value-adding energy requirement. However, when looking at transportation under energy-related aspects, the idea of the 'air cut' can in principle also be applied. Just the time and energy input which brings about a change of the location of a product is considered as necessary. The rest is considered as non necessary.

The VSM which has become common practice in the industry is, in consequence and while maintaining its inner logic, extended by adding the representation of the energy input in production and logistics processes to it. This methodical procedure provides a practical tool to process designers for a comprehensive analysis and improvement of value-streams.

Open Access This article is distributed under the terms of the Creative Commons Attribution License which permits any use, distribution, and reproduction in any medium, provided the original author(s) and the source are credited.

\section{References}

1. Bundesministerium für Umwelt, Naturschutz und Reaktor-sicherheit (2011) Umweltwirtschaftsbericht, Umweltbundesamt, p. 80, Dessau-Roßlau

2. Ohno T (1988) Toyota production system. Beyond large-scale production. Portland, OR: Productivity Press, pp ix, 19-20

3. Imai M (1997) Gemba Kaizen. A commonsense, low-cost approach to management. McGraw-Hill, pp xxvi, 22, New York

4. Schillig R, Stock T, Müller E (2013) Energiewertstrom-analyse. Eine Methode zur Optimierung von Wertströmen in Bezug auf den Zeit- und Energieeinsatz. ZWF Jahrg 107(1-2), pp 20-26

5. Womack JP, Jones DT, Ross D (1990) The machine that changed the world. Free Press, New York, p 11

6. Rother M, Shook J (2009) Learning to see. Value-stream mapping to create value and eliminate muda. Lean Enterprise Institute, Cambridge, MA

7. Müller E, Schillig R, Stock T (2012) Duale Energie-signaturen ermöglichen modifizierte Wertstromanalyse, in: Müller, Egon; Bullinger, Angelika C (Hrsg.): Intelligent vernetzte Arbeits- und Fabriksysteme. Proceedings of the 9th expert conference, Vernetzt Planen und Produzieren-VPP2012 \& 6th symposium, Wissenschaft und Praxis, Wissenschaftliche Schriftenreihe des IBF, Sonderheft 18, pp. 167-178, Chemnitz

8. Erlach K, Westkämper E (2009) Energiewertstrom. Der Weg zur Energie Effizienz Fabrik, Fraunhofer Verlag

9. Reinhart G, Karl F, Krebs P, Maier T, Niehues K, Niehues M, Reinhardt S (2011) Energiewertstromdesign. Ein wichtiger Bestandteil zum Erhöhen der Energieproduktivität. wt Werkstattstechnik online, Jahrgang 101(4):254-255 
10. Shahrbabaki SAD, Jackson M (2011) Green and lean production visualization tools; a case study exploring EVSM. In: Kersten W International supply chain management and collaboration practices, Josef Eul Verlag, Lohmar Köln, pp 399-412

11. Seai-Sustainable energy authority of ireland (2009) Value stream mapping with energy, VSMe. Roadstone Provinces, Bunratty, Co. Clare. http://www.seai.ie/Your_Business/Energy_ Agreements/Special_Working_Groups/AM_SWG_2008/roadstone_ VSM.pdf, (Accessed June, 2013)

12. EPA (2011) The lean, energy \& climate toolkit. United States environment protection agency. pp 19-22 http://www.epa.gov/ lean, (Accessed June, 2013)

13. Anvar MM, Irannejad PP (2010) Value-stream mapping in chemical processes. In: Proceedings of the 5th lean advancement initiative, Daytona Beach, Florida

14. Keskin C, Kayakutlu G (2012) Value stream maps for industrial energy efficiency. In: Proceedings of PICMENT'12: Technology management for emerging technologies, pp 2824-2831

15. Müller E, Stock T, Schillig R (2013) Dual energy signatures enable energy value-stream mapping. Proceedings of $23 \mathrm{rd}$ international conference on flexible automation and intelligent manufacturing (FAIM), Porto, Portugal

16. Schillig R, Stock T, Kalhöfer E, Kurz B (2013) Produktionsprozesse energetisch bewerten. Bilanzierung von Wertschöpfungsketten mittels dualer Energiesignaturen. Wt Werkstattstechnik online. Ausgabe 5-2013:456-463

17. Müller E, Engelmann J, Löffler T, Strauch J (2009) Energieeffiziente Fabriken planen und betreiben. Springer, Heidelberg, pp 43-44

18. Neugebauer R et al (2008) Untersuchung zur Energieeffizienz in der Produktion. Fraunhofer-Gesellschaft, chapter 6

19. Hellingrath B, Schürrer S (2009) Energieeffizienz und Umweltbilanz von Supply Chains. Software in der Logistik, p 17

20. Schenk M, Wirth S, Müller E (2010) Factory planning manual. Springer, Heidelberg, pp 10-11

21. Engelmann J (2008) Methoden und Werkzeuge zur Planung und Gestaltung energieeffizienter Fabriken. Wissenschaftliche Schriftenreihe iBF, vol 71, p 75, Chemnitz 